\title{
PENERAPAN PEMBELAJARAN KOLABORATIF PADA MATA PELAJARAN MATEMATIKA DI SMKN 1 KOTABUMI
}

\author{
Ratih Handayani ${ }^{1}$, Eka Wiwik Sulistiawati ${ }^{2}$ \\ ${ }^{1}$ STKIP Muhammadiyah Kotabumi, ${ }^{2}$ SMK Negeri 1 Kotabumi \\ email: ratihhandayani12@gmail.com
}

\begin{abstract}
The application of Collaborative Learning in mathematics subjects is a problem in this study. The purpose of this study was to find out how to apply collaborative learning in mathematics subjects at Kotabumi 1 Vocational School. The method used in this research is qualitative descriptive. The implementation of collaborative learning is carried out in the aspects of learning tools, teaching materials, learning media, and the implementation of learning. The implementation of learning in the classroom is carried out in 8 meetings Students who are the subject of research are students of class XI TKJ 1. Based on observations it can be concluded that the application of Collaborative learning can improve the quality of lecturers, teachers, and students to learn from each other in subjects.
\end{abstract}

Keyword: application, collaborative learning Tipe STAD, Lesson Study, Aljabar Linier.

\section{PENDAHULUAN}

Undang-undang no 12 tahun 2012 pasal 35 ayat 2 menegaskan bahwa kurikulum pendidikan tinggi dikembangkan oleh setiap perguruan tinggi dengan mengacu pada standar nasional pendidikan tinggi. Peraturan presiden no 8 tahun 2012 tentang Kerangka Kualifikasi Nasional Indonesia (KKNI). Perguruan tinggi sebagai penghasil SDM terdidik memiliki kemampuan yang telah dirumuskan sesuai kualifikasi dan standar kompetensi guru yang ditetapkan. Dengan demikian, dalam penyusunannya memerlukan penyesuaian pada tataran implementasi dalam program pendidikan guru.
Menyadari pentingnya hal tersebut, Kemenristekdikti melalui Belmawa mengembangkan program revitalisasi lembaga pendidikan tenaga kependidikan (LPTK) dengan memberikan program penugasan dosen ke sekolah. Dengan tujuan agar program studi sebagai bagian dari LPTK mampu menyusun kurikulum yang kompetitif, inovatif, dan relevan dengan kebutuhan nasional/lokal dan dikembangkan dari kearifan lokal. Kegiatan yang dilakukan adalah kegiatan kolaborasi antara dosen dan guru dalam proses pembelajaran. Kegiatan kolaborasi yang dilakukan oleh dosen dan guru dilakukan dalam bentuk pembuatan perang- 
kat pembelajaran, bahan ajar, dan media pembelajaran serta proses pembelajaran di kelas.

Kolaborasi adalah suatu kegiatan yang di dalamnya terdapat dua atau lebih orang belajar atau berusaha untuk belajar sesuatu secara bersama-sama. Tidak hanya siswa yang saling belajar, tetapi dosen dan juga guru harus saling belajar untuk meningkatkan kualitas. Seorang dosen tidak hanya meningkatkan pengetahuan, tetapi juga meningkatkan keterampilan membelajarkan mahasiswa sesuai dengan situasi dan kondisi saat ini yang sesuai dengan realita.

Salah satu sekolah yang memiliki kurikulum sesuai dengan kebutuhan lokal, yaitu Sekolah Menengah Kejuruan (SMK) Negeri 1 Kotabumi. SMK N 1 Kotabumi adalah salah satu sekolah di Kotabumi Lampung Utara yang memiliki nilai akreditasi A. Hal ini menunjukkan bahwa manajemen sekolah dalam mengelola pembelajaran sudah sangat baik.

Berdasarkan uraian tersebut maka akan dilakukan penelitian tentang bagaimana penerapan pembelajaran kolaboratif pada mata pelajaran matematika di SMK Negeri 1 Kotabumi.

\section{KAJIAN TEORI}

Mata pelajaran matematika adalah salah satu mata pelajaran wajib di semua jenjang pendidikan. Matematika adalah pelajaran yang membentuk cara berpikir yang sistematis, rasional, logis, dll. Selain itu matematika juga merupakan salah satu program studi yang ada di STKIP Muhammadiyah Kotabumi yang akan menghasilkan lulusan sebagai tenaga pendidik di bidang matematika. Melalui program studi matematika akan dikembangkan kurikulumnya sesuai dengan kebutuhan nasional/lokal.

Kegiatan pengembangan kurikulum pada mata pelajaran matematika dilakukan dengan melakukan pembelajaran kolaboratif. Pada pembelajaran kolaboratif tidak siswa tidak belajar sendirian. Siswa yang terlibat dalam pembelajaran kolaboratif akan memanfaatkan sumber daya dan keterampilan satu sama lain. Misalnya, dalam hal meminta informasi, mengevaluasi ide-ide, memantau pekerjaan satu sama lain, dan lain-lain.

Barkley (2014:4) dalam bukunya Collaborative Learning Techniques mengatakan berkolaborasi berarti bekerja bersama-sama dengan orang lain. Keohane dalam Budi (2013) berpendapat bahwa kolaborasi adalah bekerja bersama dengan yang lain, kerja sama, bekerja dalam begian satu team, dan di dalamnya bercampur didalam satu kelompok menuju keberhasilan bersama. Patel dalam Budi (2013) berpendapat bahwa kolaborasi adalah suatu proses saling ketergantungan fungsional dalam mencoba untuk kete- 
rampilan koordinasi, to coordinate skills, tools, and rewards.

Kolaborasi yang akan dilakukan dalam penelitian ini adalah kolaborasi antara dosen pendidikan matematika STKIP Muhammadiyah Kotabumi (selanjutnya disebut dosen pelaksana) dan guru matematika SMKN 1 Kotabumi (selanjutnya disebut guru mitra). Hal yang akan dikolaborasikan adalah perangkat pembelajaran, bahan ajar, media pembelajaran, dan proses pembelajaran di kelas.

Manfaat penerapan kegiatan penugasan dosen ke sekolah, yaitu sebagai berikut:

1. memperkuat filosofi keilmuan pendidikan, pendidikan disiplin ilmu, dan sistem pendidikan guru;

2. meningkatkan kemampuan LPTK dalam menyelenggarakan pendidikan secara profesional untuk menghasilkan guru dan tenaga kependidikan yang berkualitas;

3. menjadi rujukan dalam inovasi pembelajaran berbasis riset untuk mewujudkan pembelajaran yang efektif serta menyebarluaskan inovasi pembelajaran melalui pengabdian kepada masyarakat;

4. memperkuat kelembagaan, manajemen, sumber daya manusia, dan sumber daya lainnya;

5. meningkatkan daya saing LPTK yang disesuaikan dengan standar mutu pendidikan guru yang tinggi;

6. meningkatkan kualitas akademik dan profesionalisme lulusan LPTK.

\section{METODOLOGI PENELITIAN}

Metode yang digunakan dalam penelitian ini adalah deskriptif kualitatif. Metode deskriptif kualitatif menurut Sugiyono (2010:15) adalah metode penelitian yang berlandaskan pada filsafat positivisme. Metode ini digunakan untuk meneliti pada kondisi objek yang alamiah, (sebagai lawannya adalah eksperimen). Peneliti adalah sebagai instrumen kunci, pengambilan sampel sumber data dilakukan secara purposive dan snowball. Teknik pengumpulan data dengan triangulasi. Analisis data bersifat induktif/kualitatif, dan hasil penelitian kualitatif lebih menekan makna dari pada generalisasi.

Pelaksanaan pembelajaran kolaboratif dilakukan dalam 8 pertemuan. Siswa yang menjadi subjek penelitian adalah siswa kelas XI TKj 1 dengan jumlah 34 orang. Teknik pengumpulan data diperoleh dari hasil observasi dan catatan lapangan yang dilakukan oleh para observer.

\section{HASIL PENELITIAN}

Pelaksanaan kolaborasi dilakukan dalam beberapa aspek. Pertama penyusunan perangkat pembelajaran. Perangkat pembelajaran yang dihasilkan dalam 
program ini antara lain, silabus dan rencana pelaksanaan pembelajaran untuk 2 kompetensi dasar yang telah didiskusikan sebelumnya oleh guru mitra dan dosen pelaksana. Jadi, perangkat pembelajaran ini merupakan hasil dari diskusi antara dosen pelaksana dan guru mitra dengan memperhatikan keilmuan dan pengalaman keduanya sebagai tenaga pendidik di bidang matematika. Beberapa hal yang perlu diperhatikan saat penyusunan rencana pembelajaran ini adalah taraf kesulitan materi ajar, metode dan strategi pembelajaran yang harus mampu mengaktifkan siswa, alokasi waktu yang tersedia, dan tugas yang dapat meningkatkan kemampuan siswa, serta karakteritik siswa.

Kolaborasi berikutnya dilakukan dalam hal penyusunan bahan ajar. Bahan ajar disusun sesuai dengan kurikulum sekolah, hanya materinya lebih diperdalam sesuai konsep yang seharusnya diajarkan kepada siswa. Bahan ajar yang disusun hanya bahan ajar yang akan digunakann dalam proses penelitian, yaitu materi matriks. Selain bahan ajar kolaborasi juga dilakukan saat menyusun media pembelajaran yang akan digunakan dalam proses pembelajaran.

Proses pembelajaran di kelas dilaksanakan dengan proses kolaborasi antara guru mitra dan dosen pelaksana. Pelaksaan program ini dilakukan untuk 2 kompetensi dasar dan dilakukan dalam 8 kali pertemuan. Pertemuan pertama dilaksanakan pada tanggal 3 September dengan materi awal, yaitu definisi matriks. Saat itu yang menjadi guru 2 orang, yaitu guru mitra dan dosen pelaksana. Di akhir pembelajaran baik dosen pelaksana maupun guru mitra mengisi jurnal refleksi yang hasilnya akan digunakan untuk perbaikan dipertemuan berikutnya.

Contoh jurnal refleksi dosen yang telah tersusun adalah sebagai berikut.

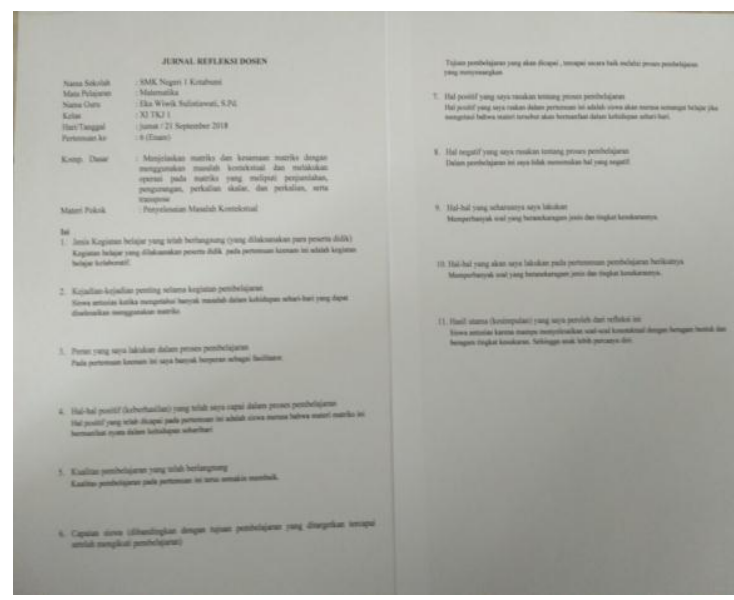

Gambar 1

Jurnal Refleksi Dosen

Pembelajaran kolaboratif dilaksanakan di kelas yang diikuti oleh 34 siswa yang terdiri 8 kelompok. Masing-masing kelompok terdiri dari 4 orang, kecuali 2 kelompok yang terdiri dari 5 orang. Pembelajaran dilaksanakan sesuai dengan langkah-langkah pembelajaran yang telah disusun. Kemudian hasil pelaksanaannya akan direfleksikan dalam jurnal. Adapun contoh jurnal refleksi guru adalah sebagai berikut. 


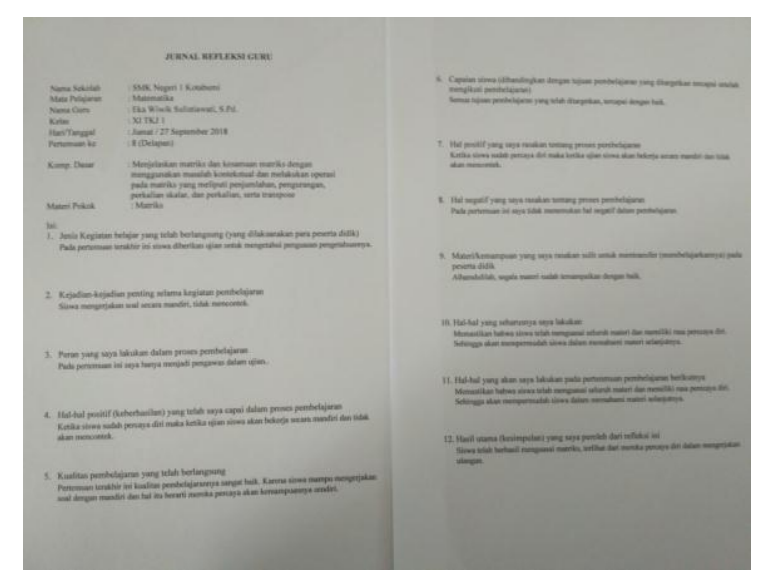

Gambar 2

Jurnal Refleksi Guru

\section{PEMBAHASAN HASIL PENELITIAN}

Penerapan pembelajaran kolaboratif pada mata pelajaran matematika merupakan sesuatu yang baru. Pembelajaran yang biasa digunakan pada mata pelajaran ini adalah pembelajaran langsung dengan satu orang guru sebagai satu-satunya sumber belajar. Hal ini menyebabkan siswa menjadi pasif dan tidak terbiasa untuk mengkonstruksi sendiri penetahuan yang didapat.

Pada pembelajaran kolaboratif ini, siswa akan diajarkan oleh 2 orang guru yang keduanya dapat menjadi sumber belajar sekaligus fasilitaor dalam pembelajaran. Yang berkolaborasi tidak hanya guru mitra dan dosen pelaksana, tetapi juga siswa akan berkolaborasi satu sama lain untuk berdiskusi menyelesaikan Lembar Kerja yang dibagikan. Jika dalam kelompoknya siswa mengalami kesulitan, siswa diperbolehkan untuk bertanya kepada kelompok lain. Apabila semua kelompok mengalami kesulitan baru dipersilahkan bertanya kepada guru.

Pada pertemuan pertama, hasil refleksi menunjukkan beberapa hal yang belum cukup baik. Misalnya siswa masih terlihat kaku dalam pembelajaran, hal ini dikarenakan siswa siswa tidak terbiasa dengan 2 orang guru didalam kelas. Pada saat bekerja dalam kelompok pun, siswa tidak aktif berdiskusi dalam menyelesaikan lembar kerja. Kolaborasi antara guru mitra dan dosen pelaksana pun dalam penyampaian materi di kelas belum terlalu baik. Pembelajaran masih didominasi oleh guru mitra. Hal ini dapat dilihat dari hasil refleksi dosen sebagai berikut.

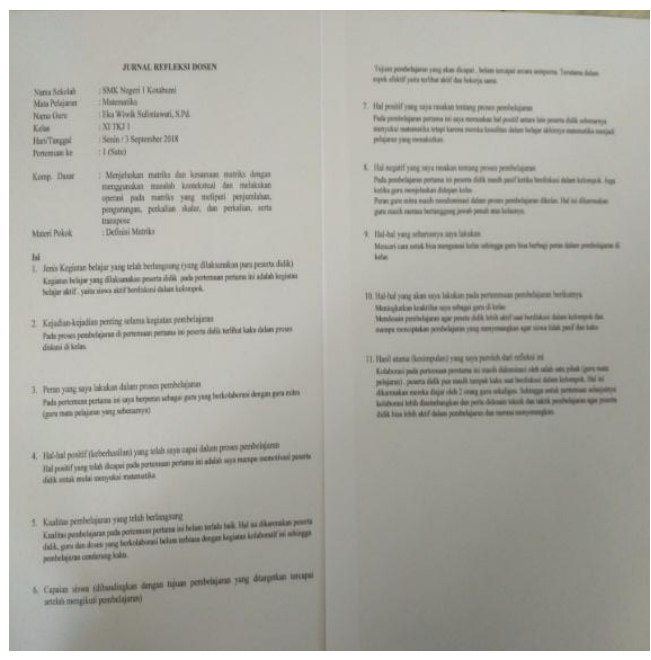

Gambar 3

Jurnal Refleksi Dosen

Hasil refleksi tersebut digunakan sebagai perbaikan pada pertemuan berikutnya, yaitu untuk meningkatkan keaktifan dosen sebagai guru di kelas. Selain itu juga untuk mendesain pembelajaran agar peseta didik lebih aktif saat berdiskusi dalam 
kelompok dan mampu menciptakan pembelajaran yang menyenangkan dan interaktif agar siswa tidak pasif dan kaku.

Pada pertemuan yang selanjutnya, ada beberapa kemajuan yang diperoleh, antara lain. Ada beberapa kelompok yang sudah aktif berdiskusi dalam kelompoknya. Bahkan, adapula yang ketika kelompoknya mengalami kesulitan maka kelompok tersebut bertanya ke kelompok lain. Hal ini baik karena peran dosen dan guru sebagai sumber ilmu sudah berkurang. Kemudian ketika proses penyimpulan mahasiswa menyampaikan hasil diskusi nya dengan baik dan siswa tampak puas dengan hasil diskusinya. Namun, masih ada beberapa hal yang pelu diperbaiki, yaitu ada beberapa mahasiswa yang masih pasif dalam kegiatan diskusi.

Hasil refleksi pada pertemuan sebelumnya terus diperbaiki dalam perencanaan pertemuan selanjutnya, sehingga pertemuan-pertemuan berikutnya semakin berkualitas. Beberapa kemajuan yang dicapai siswa antara lain: diskusi berjalan dengan baik, terlihat siswa antusias, siswa lebih rileks dalam pembelajaran. Pada pertemuan terakhir, pelaksanaannya semakin baik, terlihat dari hasil refleksi guru yang menyatakan bahwa siswa telah percaya diri saat mengerjakan ujian. Hal ini dikarenakan siswa telah menguasai konsep materi pelajaran dengan baik.

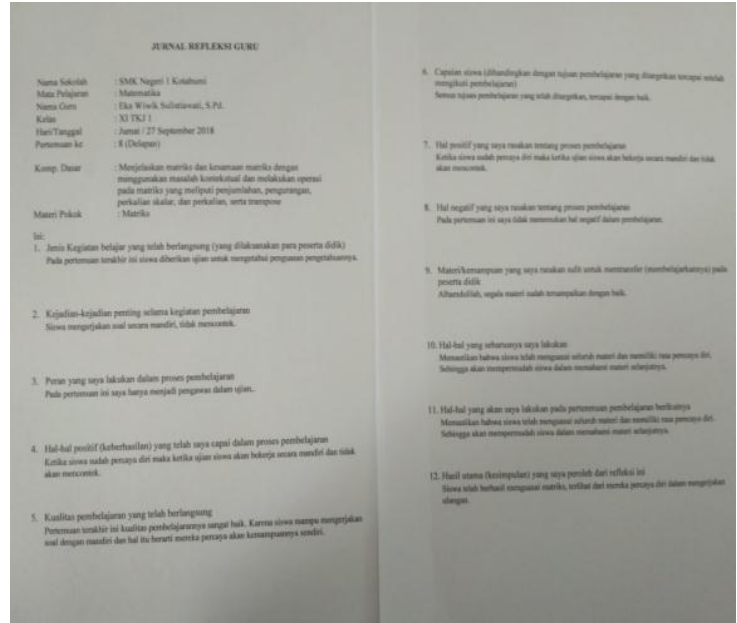

Gambar 4

Jurnal Refleksi Guru

\section{SIMPULAN DAN SARAN}

\section{Simpulan}

Berdasarkan hasil amatan pada jurnal refleksi dosen maupun jurnal refleksi guru maka penerapan pembelajaran kolaboratif pada mata pelajaran matematika di SMKN 1 Kotabumi dapat membantu dosen dan guru untuk saling belajar mendesain pembelajaran yang sesuai dengan kebutuhan lokal. Hal ini akan digunakan sebagai bahan untuk mengembangkan kurikulum di program studi pendidikan matematika khususnya, dan STKIP Muhammadiyah Kotabumi sebagai LPTK yang menghasilkan lulusan sebagai tenaga pendidik umumnya. Pada akhirnya Penerapan pembelajaran kolaboratif pada mata pelajaran matematika di SMKN 1 Kotabumi memberikan peningkatan kualitas pada STKIP Muhammadiyah Kotabumi, dosen, guru, dan juga siswa. 
Saran

Berdasarkan hasil penelitian dan pembahasan agar mendapatkan hasil yang lebih optimal disarankan hal-hal berikut ini.

1. Dosen dapat menerapkan pembelajaran kolaboratif untuk meningkatkan kualitas mengajar dan menambah wawasan tentang dunia sekolah.

2. Pembaca dan peneliti lain yang ingin mengembangkan penelitian lanjutan mengenai pembelajaran kolaboratif, hendaknya melakukan pembiasaan pembelajaran terlebih dahulu dan membuat buku tuntunan guru dan siswa. Buku tersebut digunakan sebagai wadah bagi guru untuk mencatat atau melihat kekurangan maupun perkembangan belajar siswa secara berkelanjutan dan untuk melihat keterlaksanaan pembelajaran yang diterapkan oleh guru

\section{DAFTAR RUJUKAN}

Elizabert E. Barkley, K. Patricia Cross, Clarie Howell Major. 2014. Collaborative Learning Techniques. Bandung: Nusa Media.

Rusman. 2010. Model-Model Pemebelajaran Mengembangkan Profesionalisme Guru. Bandung: Raja Grafindo Persada.

Sugiono. 2010. Metode Penelitian Kuantitatif Kualitatif Dan R\&D. Bandung: Alfabeta.

Trianto. 2009. Mendesain Model Pembelajaran Inovatif-Progesif. Jakarta: Kencana.

https://kurniawanbudi04.wordpress.com/2013/05/27/collaborative-learning/ 